\title{
foundation stiffness on the behaviour of surface strip foundations on sand
}

\author{
H E Lemmen, S W Jacobsz, E P Kearsley
}

The objective of this study was to determine whether the contact stress distribution underneath a strip footing on dense cohesionless sand can be predicted as a function of the properties of the footing and that of the underlying sand. Together, the footing and the underlying sand form a foundation system which can be classified in terms of relative stiffness. Centrifuge model tests were conducted on seven aluminium footings of various depths and hence stiffness, and one reinforced concrete footing, during which the qualitative variation in contact stress distribution underneath the footing was captured with the use of Tekscan ${ }^{\mathrm{TM}}$ pressure sensors.

It was found that, as long as the relative stiffness of the foundation classifies as "stiff", the contact stress distribution underneath the footing is approximately uniform. As the relative foundation stiffness is reduced, the contact stress underneath the footing edge as a percentage of the maximum stress occurring underneath the column, reduces. In the case of a semi-flexible footing tested, zero pressure was measured underneath the footing edge in response to loading of the footing. An expression is presented to allow the contact stress under the edge to be estimated as a function of the relative stiffness of the foundation. This allows the contact stress distribution underneath semi-stiff footings to be estimated.

The stiffness of the model reinforced concrete footing tested reduced considerably due to cracking during loading. It is recommended that footings be provided with sufficient stiffness to classify as stiff. A modification of the benchmark value for the minimum relative stiffness classifying as stiff is proposed, based on the results of the centrifuge tests.

\section{INTRODUCTION}

A foundation system consists of the combination of the soil supporting a structure and a footing that spreads the imposed load of the structure over a volume of soil large enough to form a stable system. Aspects typically considered during the design of a foundation system are ultimate bearing capacity and serviceability (i.e. an upper limit on the acceptable settlement) (Aiban \& Znidarčic 1995), with the settlement performance of the system generally being the governing factor. When a foundation system is designed, it is difficult to accurately determine the material properties of the soil in the system, whereas the properties of the materials used to construct the footing in a foundation system can be quantified fairly accurately.

To simplify the design of a foundation system, structural engineers regularly model the material behaviour of the soil as a system of linear springs. The linear spring model delivers fairly accurate settlement and deflection results when relatively small strains are present within the soil mass (Conniff \& Kiousis 2007). This system can, however, not accurately predict inelastic material behaviour in response to loading, and is difficult to use for modelling problems which approach the ultimate bearing capacity of a foundation system. Also, it cannot take strain compatibility below and adjacent to the foundation into account, as it does not model lateral soil response.

Structural engineers often increase the depth (thickness) of a footing to improve shear performance. However, there is no limit to the extent to which the depth can be increased. To obtain the most economical foundation design, an optimum footing depth for a given soil stiffness can be determined.

The extent to which an increase in the footing depth would improve the performance of a foundation system was investigated, as well as the effect of the overall foundation stiffness on the deformation of and stress distribution beneath the footing. The focus of this investigation was limited to strip footings on dense cohesionless sand underlain by a rigid base.

\section{BACKGROUND}

The basis on which reinforced concrete footings or slabs are designed was first pioneered by Westergaard (1925). Through the

\section{JOURNAL OF THE SOUTH AFRICAN INSTITUTION OF CIVIL ENGINEERING} ISSN 1021-2019

Vol 59 No 2, June 2017, Pages 19-27, Paper 1423

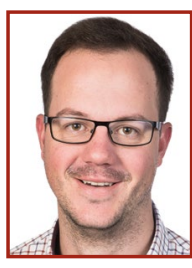

EDUARD LEMMEN, who is a member of the South African Institution of Civil Engineering (SAICE), received his BEng in Civil Engineering in 2012 and an MEng (Structural Engineering) in 2015, both from the University of Pretoria. This paper is based on research conducted for his Master's degree. He is currently working as structural engineer at EDS Engineering.

Contact details:

EDS Structural, Civil \& Transportation Engineers

PO Box 33920

Glenstantia

Pretoria

0010

South Africa

T: +27129911205

E: eduardlemmen@icloud.com

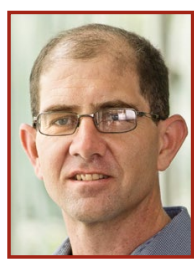

PROF SW JACOBSZ is a member of the South African Institution of Civil Engineering (SAICE). He graduated with an MEng (Geotechnical Engineering) from the University of Pretoria in 1996 and a PhD from the University of Cambridge in 2003. He is Associate Professor in the Department of Civil Engineering at the University of Pretoria, with 20 years of design and research experience in industry and academia.

Contact details:

Department of Civil Engineering

University of Pretoria

Pretoria

0002

South Africa

$\mathrm{T}:+27124203124$

E: sw.jacobsz@up.ac.za

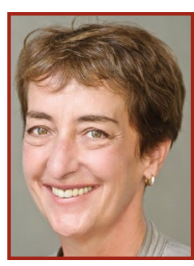

PROF ELSABÉ KEARSLEY is a Fellow of the South African Institution of Civil Engineering (SAICE), and she is currently Professor in Civil

Engineering at the University of Pretoria. She holds a PhD from the University of Leeds. She worked as a structural design engineer in both South Africa and the United Kingdom before becoming a staff member at the University of Pretoria. She was the 2009 President of the South African Institution of Civil Engineering (SAICE). For the last 23 years she has been involved with cement and concrete materials research.

Contact details:

Department of Civil Engineering

University of Pretoria

Pretoria

0002

South Africa

T: +27 124202176

E:elsabe.kearsley@up.ac.za 
study of concrete pavements he presented a mathematical model to compute the stresses in a concrete slab by assuming that the slab acts as an isotropic, homogeneous, elastic solid, and that the subgrade reaction is perfectly vertical and proportional to the size of the slab. He assumed that the subgrade was an elastic medium, where the stiffness of the subgrade could be considered as the force which would cause unit deflection if it were spread over a unit area. Westergaard (1937) also proposed a measure of the stiffness of the subgrade compared to the stiffness of the foundation, termed the radius of relative stiffness. The work done by Westergaard has been refined over the years through analytical models and experimental procedures, and it still remains the basis of a large number of design procedures (Hemsley 2000).

For the design of footings from a structural engineer's point of view, the footing is often considered as a rigid body resting on an elastic medium. This leads to the assumption that the vertical settlement of the footing on the elastic medium must have a planar distribution, because a rigid structure remains planar when it settles. The planar distribution theory is based on the assumption that the ratio of pressure to settlement remains constant, and that the stress distribution below the rigid footing is uniform. However, these assumptions are not necessarily true, as experimental studies have shown that soil exhibits plastic behaviour, footings have a finite stiffness and the distribution of pressures below a footing varies with time. The pressure distribution in the soil is a function of the type of soil (i.e. sand or clay), as well as the stiffness of the footing and superstructure (Algin 2007).

Currently footing design is based on an iterative process where the required size of the footing often relies on the engineer's educated guess. The size of the footing is then checked to see whether it satisfies the serviceability conditions and that the bearing capacity of the soil is not exceeded (usually not critical). As soon as the size of the footing has been confirmed as adequate, the depth of the footing is determined to ensure that it has adequate flexural, shear and punching shear strength to resist the applied loading conditions (Algin 2007). It is assumed that sufficient structural depth at the column will provide the footing with adequate shear, diagonal tension, and bending moment capacity (Pisanty \& Gellert 1972). The current design procedure for surface footings does not take the stiffness of either the footing or the soil into account, but rather focuses on the strength of the reinforced concrete and the allowable bearing capacity of the soil. The strength and behaviour of the footing are also considered to remain constant regardless of the applied load.

Footings are often analysed and designed using the Winkler hypothesis, where the soil is modelled as a continuous system of non-connected discrete springs. Due to the simplicity of the Winkler model, it is used extensively to solve soil-structure interaction problems and has produced satisfactory results in many cases (Morfidis \& Avramidis 2002). The Winkler approach yields relatively accurate results if the structure does not yield at any point. However, it becomes less applicable if the load keeps on increasing beyond yielding (Baumann \& Weisgerber 1983). The Winkler method is a very basic simplification of the behaviour of the soil under loading conditions (Morfidis \& Avramidis 2002). As load transfer occurs between the footing and the soil, the foundation deforms, causing internal forces to change within the structure, thus creating a complex soil-structure interaction. The significance of this interaction is important for both dynamic and static loading conditions. The most important aspect of the soilstructure interaction is the contact stress distribution beneath the footing (Conniff \& Kiousis 2007). The relationship between the stiffness of the footing and the soil controls the contact stress distribution beneath the footing (Aiban \& Znidarčic 1995; Arnold et al 2010).

The structural behaviour of a footing can largely be attributed to the stiffness thereof. It is important to consider the stiffness of the entire foundation system, and not just the stiffness of the footing. Arnold et al (2010) conducted a series of centrifuge model experiments to determine the effect of the system stiffness on the stress distribution below the footing. From their analysis they found that the stress distribution below the footing is dependent on the stiffness of the footing, as well as the footing settlement for similar soil conditions. Whether or not a foundation behaves in a flexible or rigid fashion can be assessed using a dimensionless parameter $K_{s}$ that incorporates a representative Young's modulus for the soil, combined with terms representing the stiffness of the footing in order to determine an equivalent system stiffness (Canadian Foundation Engineering Manual 2006). The stiffness parameter $K_{s}$ is calculated using Equation 1 (Arnold et al 2010). The stiffness of the system can be classified based on the ranges for $K_{s}$ given in Table 1.

$K_{s}=\left(\frac{1}{12}\right)\left(\frac{E_{b}}{E_{s}}\right)\left(\frac{d}{l}\right)^{3}$
Where:

$K_{s}=$ System stiffness

$E_{b}=$ Young's modulus of the footing

$E_{s}=$ Secant modulus of the soil

$d=$ Depth of the footing

$l=$ Width of the footing

Table 1 Stiffness limits for foundation systems (Arnold et al 2010)

\begin{tabular}{|c|c|}
\hline $\boldsymbol{K}_{\boldsymbol{s}}$ range & System stiffness \\
\hline 0 & Absolutely flexible \\
\hline $0-0.01$ & Semi-flexible \\
\hline $0.01-0.1$ & Semi-stiff \\
\hline 0.1 -infinity & Stiff \\
\hline
\end{tabular}

Arnold et al (2010) concluded that the stress distribution below a footing on sand is dependent on the magnitude of the load applied to the footing. Initially the behaviour of a footing represents that of a stiff system, and changes to flexible with an increase in the applied load. The use of a single system stiffness parameter is therefore not adequate, as it does not take the applied load into account (Arnold et al 2010). The constant stiffness typically assumed for a reinforced concrete structure is also not valid, as its stiffness is significantly influenced by nonlinearity in the concrete's material properties associated with cracking. The stiffness of a footing changes when the concrete starts to crack (Skorpen \& Dekker 2014).

The aim of the current investigation was to determine how changes in the stiffness of strip footings affect the deformation of such footings and the resulting contact stress distribution underneath during loading. This was investigated by testing a range of footings of various depths in a physical model study. The study modelled strip footings on dense sand. In further discussion in this paper the term "footing" refers to the concrete slab bearing on the soil and the term "foundation" refers to the combination of the footing and the underlying soil.

\section{EXPERIMENTAL SETUP}

\section{Description of centrifuge model}

A physical model was developed in which footings of various depths on dense sand could be loaded under plane-strain conditions. Due to the non-linear stress-strain properties of soils, the model was tested in a geotechnical centrifuge at the appropriate acceleration to correct the stress distribution to that of the full-scale prototype following Schofield (1980). Physical models examining the behaviour of shallow foundation in the 


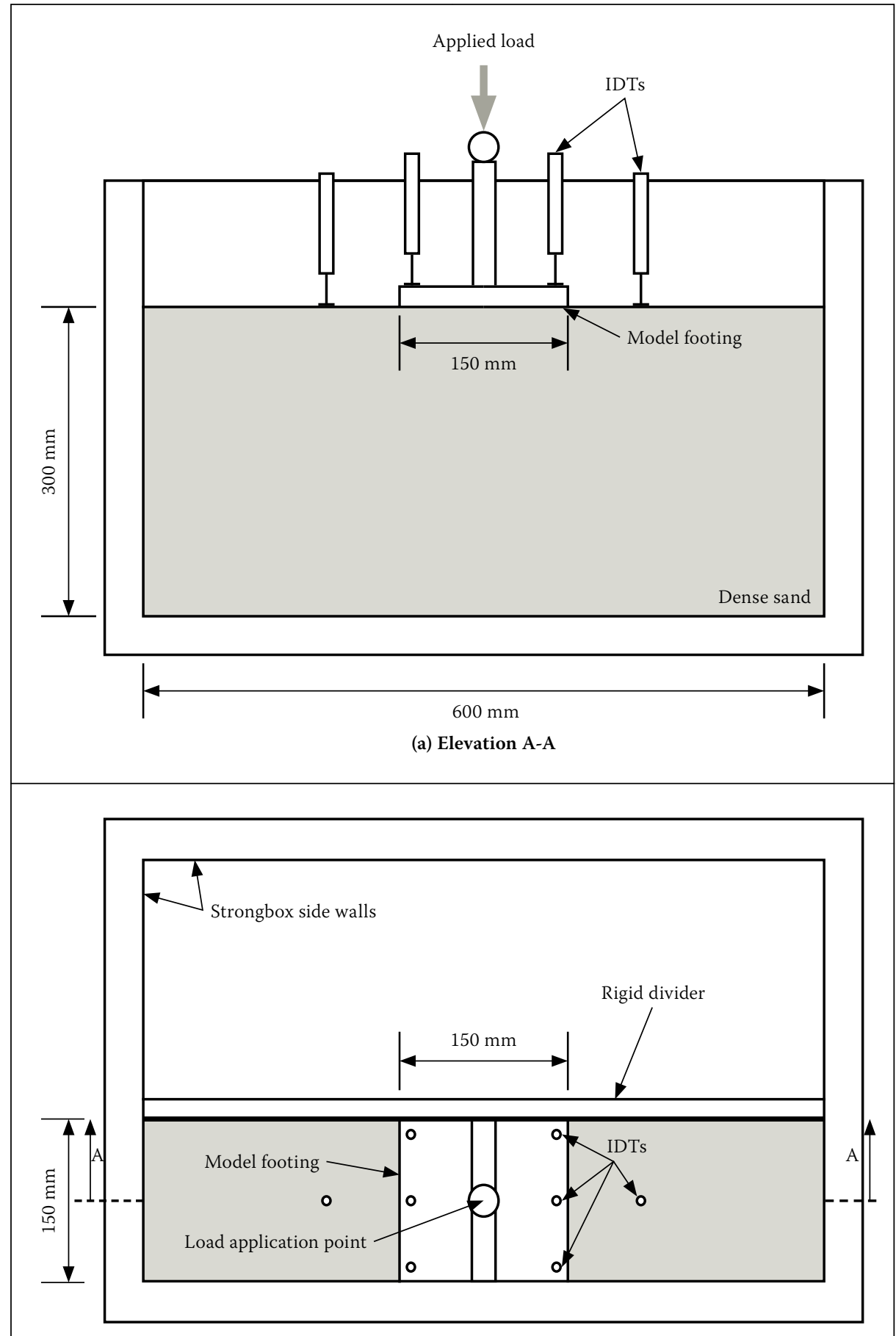

(b) Plan

Figure 1 Schematic elevation A-A (a) and plan (b) views of the centrifuge model

geotechnical centrifuge have been reported by many researchers, e.g. Kusakabe (1995), Brown et al (2004), Haigh et al (2010) and others.

A model scale of 1:30 was selected, based on practical considerations, and all models were therefore tested at an acceleration of $30 \mathrm{~g}$. It was intended to study the behaviour of strip foundations. The model was set up in a $150 \mathrm{~mm}$ wide compartment in a strongbox equipped with a glass window through which the foundation could be observed.

The length and height of the model compartment were $600 \mathrm{~mm} \times 400 \mathrm{~mm}$ respectively.

The depth of sand in the model was $300 \mathrm{~mm}$. The model is illustrated in Figure 1. are similar (Knappett et al 2010). The only physical property of the aluminium other than density necessary for this work is the Young's modulus which was measured at $70 \mathrm{GPa}$.

Because the majority of structural footings comprise reinforced concrete, the variation in the pre- and post-cracking behaviour of reinforced concrete complicates behaviour. It was therefore decided to carry out one additional test on a reinforced concrete model footing to compare behaviour with that of the much more ductile aluminium footings. The compressive strength of the concrete used for this footing was measured as $30 \mathrm{MPa}$, the modulus of elasticity $25 \mathrm{GPa}$ and the measured flexural strength approximately 4.5 MPa. The footing was reinforced with 19 steel wires of $0.71 \mathrm{~mm}$ diameter spaced at $7.5 \mathrm{~mm}$, spanning the width of the footing. Their yield stress was measured at $400 \mathrm{MPa}$ and the measured Young's modulus was $165 \mathrm{GPa}$. The reinforcement was placed with $2.5 \mathrm{~mm}$ cover to the base of the footing. The footing was $30 \mathrm{~mm}$ deep.

\section{Instrumentation and actuation}

A tactile pressure sensor mat by Tekscan ${ }^{\mathrm{Tm}}$ (2014) was placed underneath each model footing to record the contact stress during tests. The model was observed from the side through the glass window in the strongbox using a high-resolution digital camera. The images recorded enabled displacement of the sand and the footing to be tracked by means of Particle Image Velocimetry (PIV) (White et al 2003). In addition, the settlement of the footing and the adjacent sand surface were monitored using inductive displacement transducers (IDTs), as illustrated in Figure 1.

The footing was loaded by means of a purpose-built actuator driven with a stepper motor. The applied load was measured using a load cell and the imposed displacement by means of a displacement transducer incorporated into the actuator. Load application occurred in displacement control during which the actuator moved at a rate of approximately $0.01 \mathrm{~mm}$ per second. A maximum load of $30 \mathrm{kN}$ was applied, exerting an average contact stress of $1333 \mathrm{kPa}$ under the footing, considerably exceeding the typical allowable bearing capacity of sand applicable to this situation of $600 \mathrm{kPa}$ (see BSI 2015).

\section{Sand properties}

The experimental work described in this paper was carried out using a fine silica from a commercial source near Cullinan, east of Pretoria. The properties were reported by Archer (2014). The median particle size $\left(D_{50}\right)$ was $0.135 \mathrm{~mm}$. The particle size distribution of the sand is presented in Figure 3. 
The maximum and minimum relative densities were determined using ASTM D4253 (ASTM 1996a) and ASTM D4254 (ASTM 1996b) respectively at $1669 \mathrm{~kg} / \mathrm{m}^{3}$ and $1392 \mathrm{~kg} / \mathrm{m}^{3}$. The specific gravity of the grains was 2.67 .

As discussed earlier, the structural behaviour of a footing is dependent on the properties of the soil on which it is constructed. In order to characterise the relative stiffness of a foundation, a representative secant Young's modulus is required for the soil (in this case, the sand). Representative Young's moduli for each experiment were back-calculated from elastic solutions by Milovic et al (1970) based on the load-settlement response observed during the tests. Milovic's solution applies to rigid strip footings underlain by an elastic layer of finite thickness and is given below:

$E=\frac{P}{\rho_{z}} \omega_{0}$

Where: $E$ is the Young's modulus, $P$ the load intensity applied to the strip in $\mathrm{kN} / \mathrm{m}, \rho_{z}$ the observed settlement, and $\omega_{0}$ a factor that depends on Poisson's ratio (assumed to be 0.2 ) and the ratio between the strip width and the layer thickness.

The load-displacement curves observed during loading of the model footings were remarkably linear over the load ranges applied (see below), which made the choice of applied load and corresponding settlement increment for the calculation of modulus values straightforward. Table 2 summarises various foundation properties, calculated moduli, relative foundation stiffnesses calculated from Equation 1 and the stiffness classifications from Table 1.

\section{RESULTS}

\section{Load-settlement response of aluminium footings}

The footing settlements as measured at the column edge, normalised by the footing width, are presented in Figure 4 for the various footing depths tested.

The settlement of all footings initially increased approximately linearly, with an increase in the applied load over the load range tested. However, in the case of the $3 \mathrm{~mm}$ deep footing, settlement measured at the column edge began to accelerate and became non-linear after approximately $8 \mathrm{kN}$ as the footing began to bend, suffering plastic deformation. The load displacement results show that, with increasing footing depth, the settlement under a given applied load reduced, but only up to a point. The results show that, once the footing classified as stiff

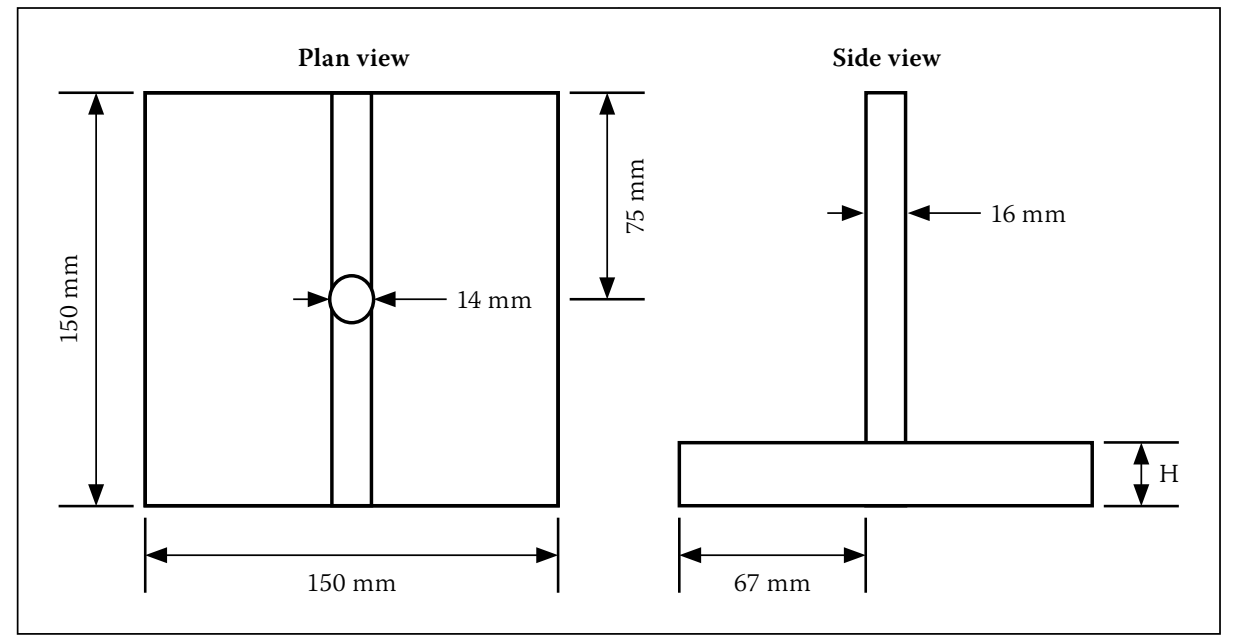

Figure 2 Model footing geometry

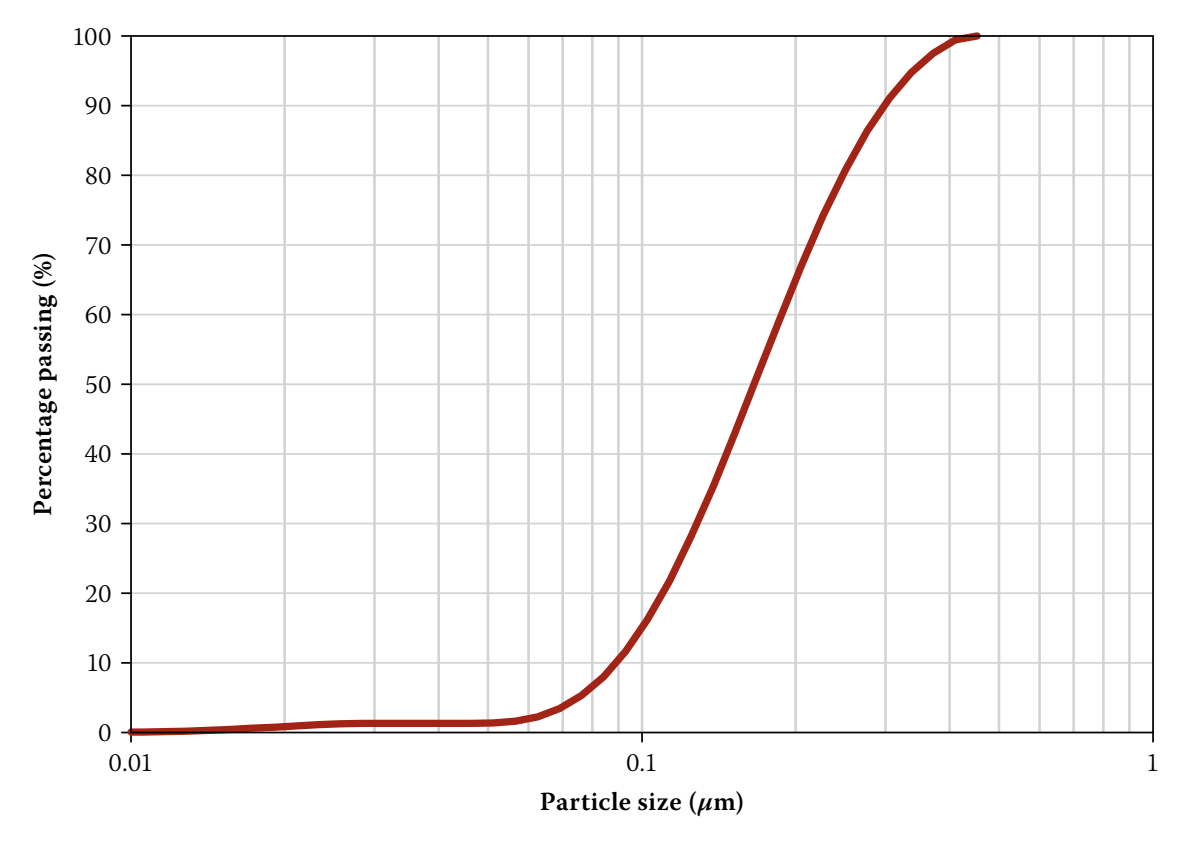

Figure 3 Particle size distribution of Cullinan sand used in centrifuge tests

Table 2 Model foundation properties

\begin{tabular}{|c|c|c|c|c|c|}
\hline Model footing & $\begin{array}{l}\text { Sand density } \\
\qquad\left(\mathrm{kg} / \mathrm{m}^{3}\right)\end{array}$ & $\begin{array}{c}\text { Sand } \\
\text { relative } \\
\text { density } \\
(\%)\end{array}$ & $\begin{array}{c}\text { Back- } \\
\text { calculated } \\
\text { secant Young's } \\
\text { modulus for } \\
\text { sand } \\
(\mathrm{MPa})\end{array}$ & $\begin{array}{c}\text { Relative } \\
\text { stiffness } \\
K_{s}\end{array}$ & $\begin{array}{c}\text { Relative } \\
\text { foundation } \\
\text { stiffness } \\
\text { classification }\end{array}$ \\
\hline $3 \mathrm{~mm}$ (aluminium) & 1578 & 67 & 18.4 & 0.003 & Semi-flexible \\
\hline $6.7 \mathrm{~mm}$ (aluminium) & 1587 & 70 & 35.6 & 0.015 & Semi-stiff \\
\hline $10 \mathrm{~mm}$ (aluminium) & 1560 & 61 & 40.5 & 0.043 & Semi-stiff \\
\hline 16 mm (aluminium) & 1587 & 70 & 47.4 & 0.149 & Stiff \\
\hline 25 mm (aluminium) & 1587 & 70 & 47.4 & 0.569 & Stiff \\
\hline 35 mm (aluminium) & 1577 & 67 & 47.4 & 1.562 & Stiff \\
\hline $50 \mathrm{~mm}$ (aluminium) & 1587 & 71 & 47.4 & 4.555 & Stiff \\
\hline $30 \mathrm{~mm}$ (concrete) & 1548 & 56 & 32.2 & $0.5181^{*}$ & Stiff* \\
\hline
\end{tabular}




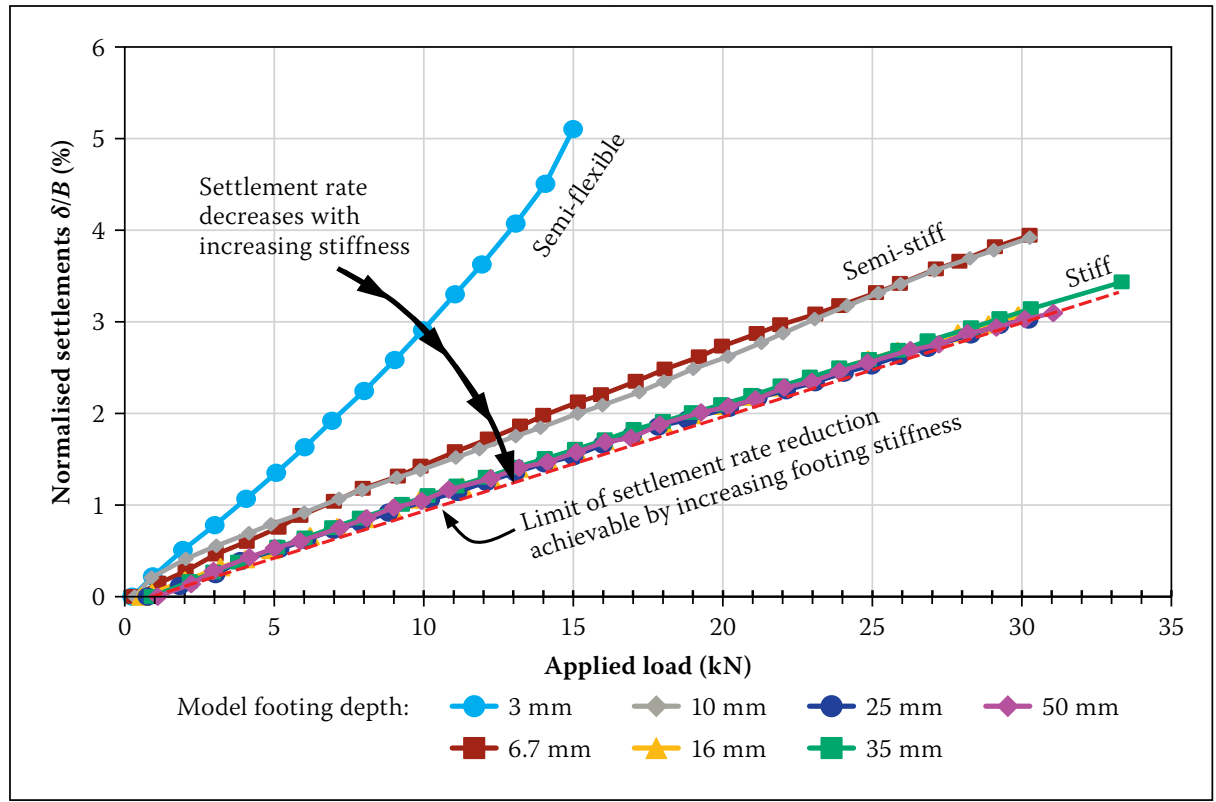

Figure 4 Normalised load-settlement response for aluminium footings of varying depth

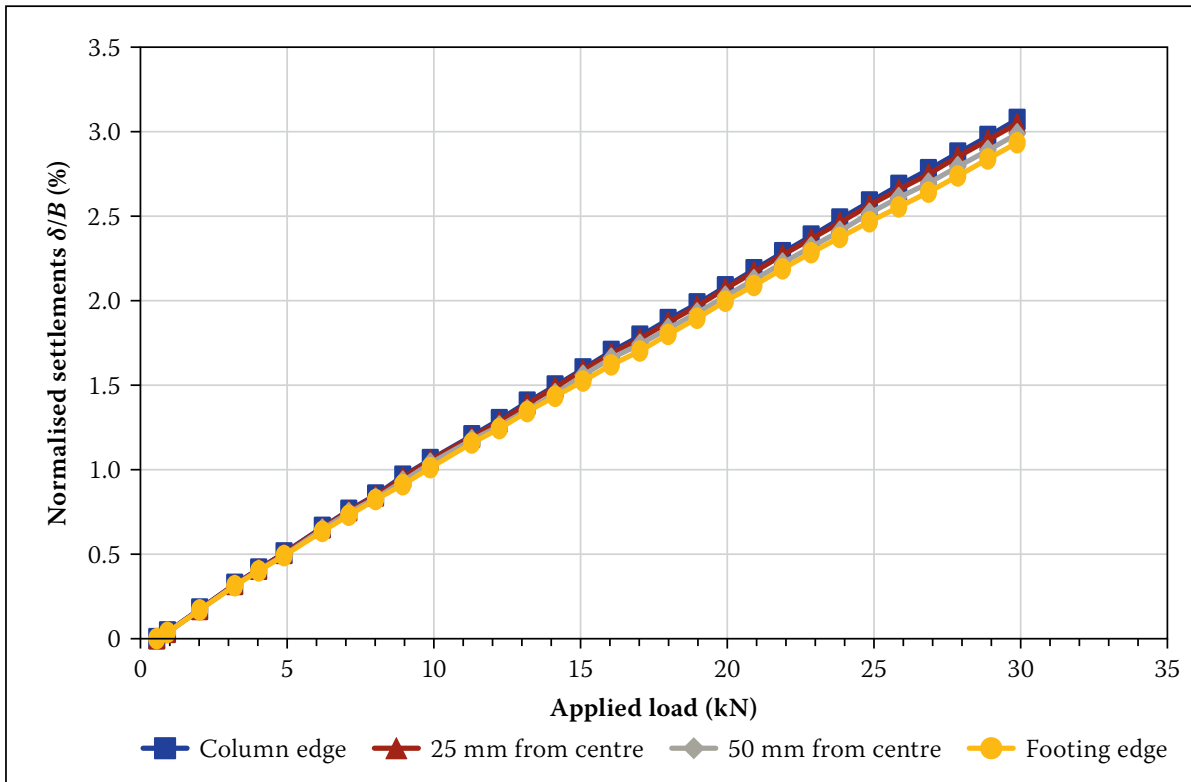

Figure 5 Normalised settlement of $16 \mathrm{~mm}$ thick aluminium footing

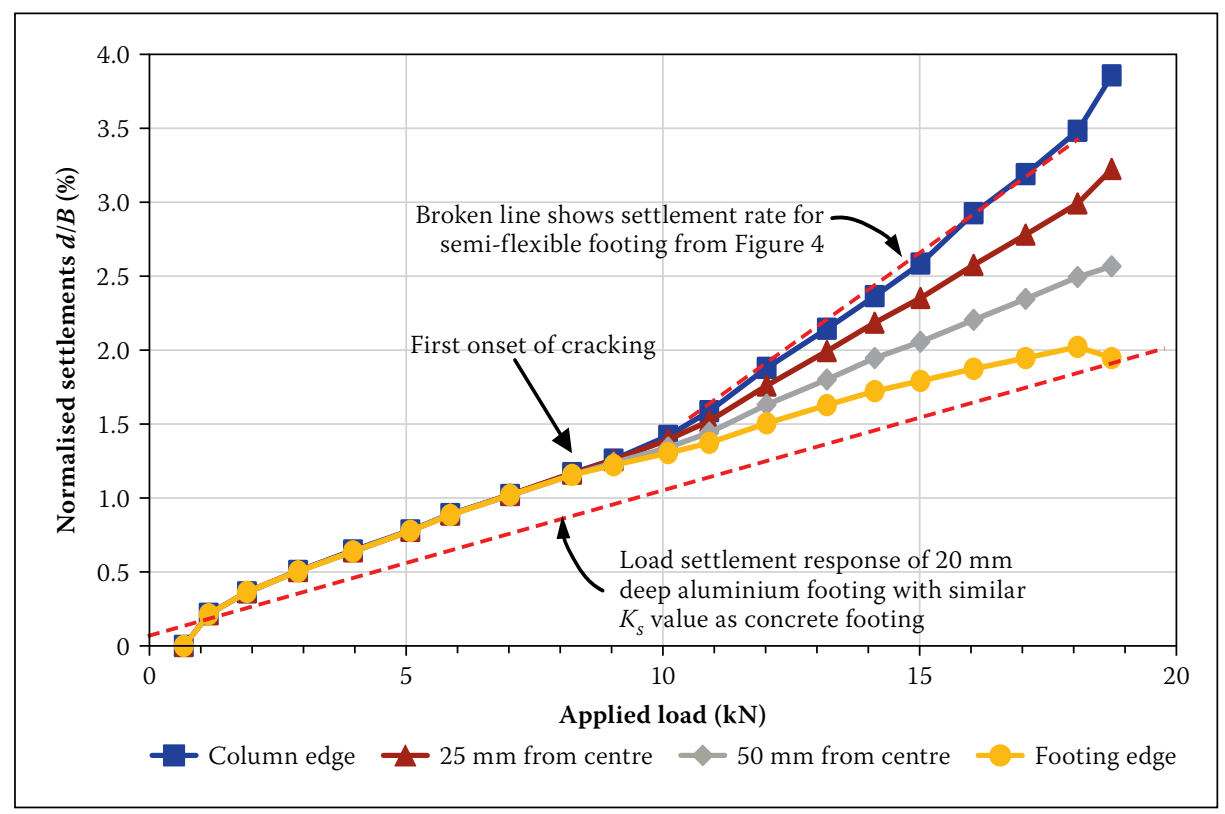

Figure 6 Normalised settlement of reinforced concrete footing (i.e. for footing depths of $16 \mathrm{~mm}$ and higher), the load-settlement response could not be improved by making the footing any stiffer, given the properties of the sand as tested.

Careful examination of the $16 \mathrm{~mm}$ deep footing showed, however, that it did not behave entirely rigidly. Figure 5 presents the settlement measured across the width of the footing at third points, showing slight variation and hence bending of the footing at larger loads. This suggests that the classification system by the Canadian Foundation Engineering Manual (2006) could perhaps be refined somewhat at the boundary separating semi-stiff and stiff footings.

\section{Load-settlement response of the reinforced concrete footing}

In addition to the investigation of the influence of footing rigidity using aluminium footings, one test was carried out using a footing made from scaled-down reinforced concrete. The depth of the reinforced concrete footing was chosen so that, for an uncracked section, the foundation system classified as stiff $\left(K_{s}\right.$ value of 0.52 ), as concrete foundations in reality would be expected to be stiff. The uncracked bending stiffness $(E I)$ of the reinforced concrete footing was similar to that of an aluminium footing with a depth of $21.3 \mathrm{~mm}$.

The normalised settlements measured at third points along the width of the reinforced concrete footing are presented in Figure 6. The onset of cracking seems to occur at an applied load of approximately $8 \mathrm{kN}$, i.e. a contact stress of $356 \mathrm{kPa}$. This stress is well below the allowable stress of approximately $600 \mathrm{kPa}$ for a dense sand calculated using the safety factor of 3 with the factors by Meyerhof (1963) or Brinch Hansen (1968) and recommended by BSI (2015). This indicates that cracking can affect the performance of a foundation in its working stress range.

A clear difference in the response of the footing is evident prior to and after cracking. The applied load was increased to $18.7 \mathrm{kN}$ (average contact stress of $832 \mathrm{kPa}$ ), beyond which the footing was unable to accept additional load and just continued to deform. Cracking of the footing resulted in the footing effectively changing from stiff to much more flexible. The settlement rate for the $3 \mathrm{~mm}$ deep footing, which classified as semiflexible, is presented against the settlement record of the concrete footing measured at the column edge for comparison. This illustrates that, after cracking, the loadsettlement response of the concrete footing effectively became semi-flexible.

\section{Contact stress distribution}

The contact stress distribution underneath each model footing was measured using a 


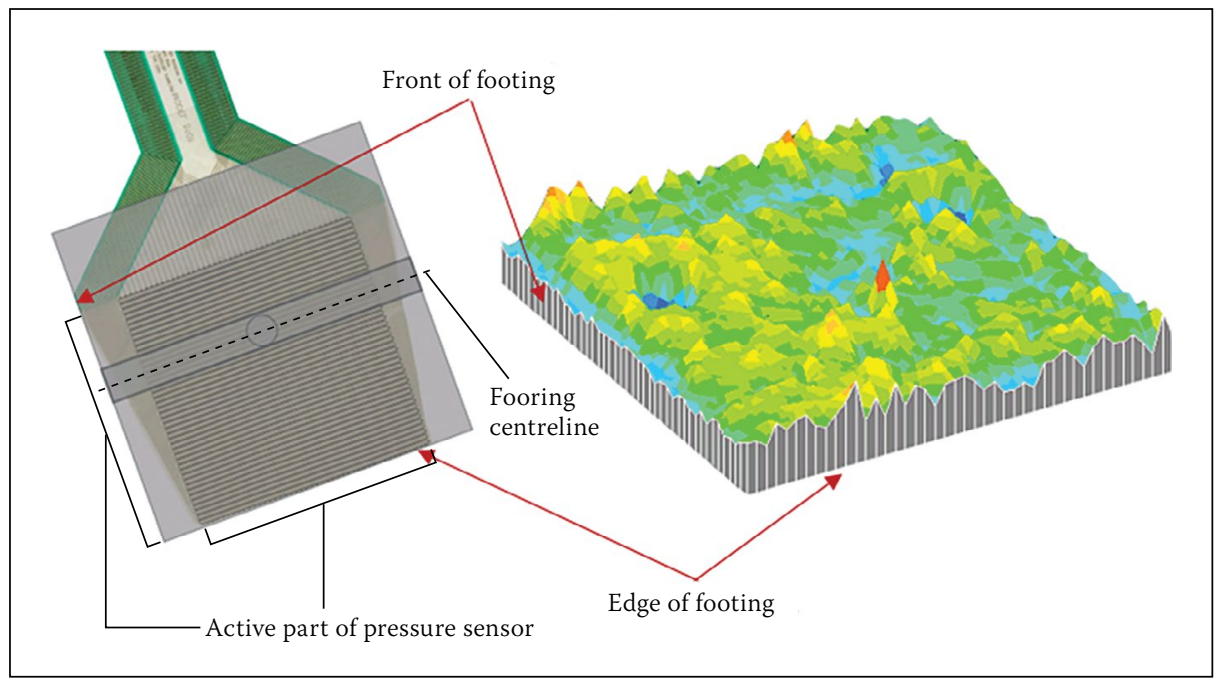

Figure 7 Position of pressure sensors under footings

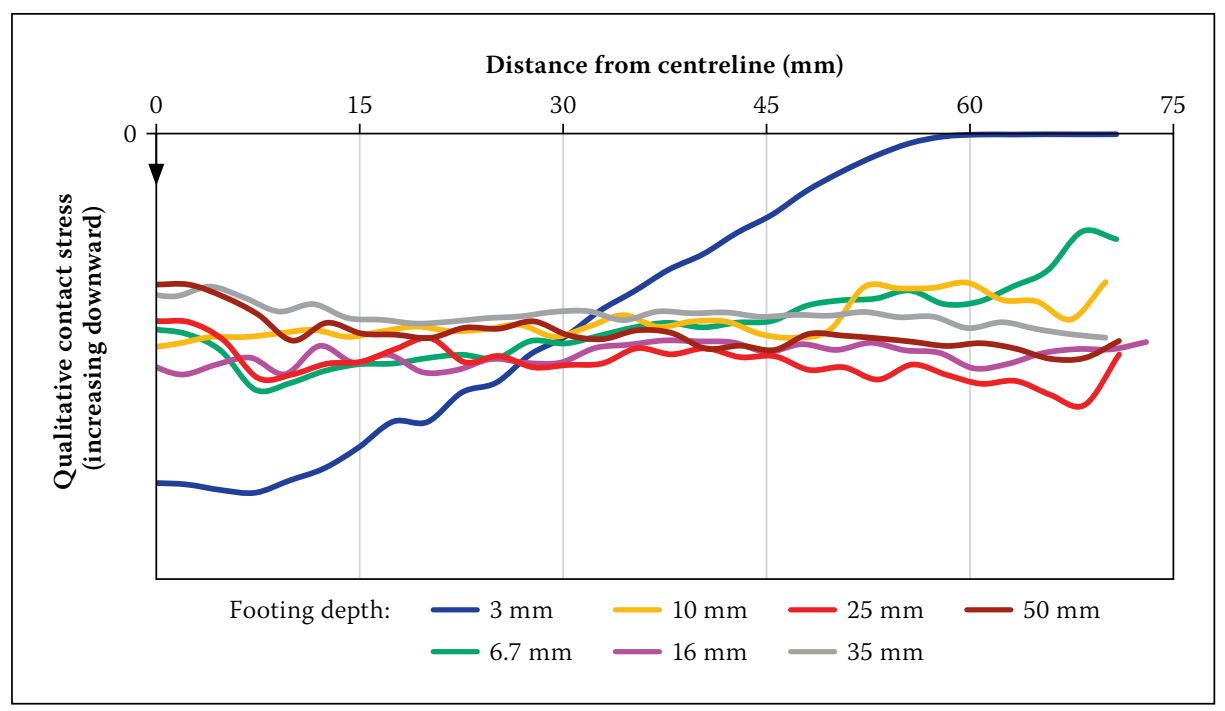

Figure 8 Qualitative contact stress distribution under aluminium footings at $10 \mathrm{kN}$ applied load

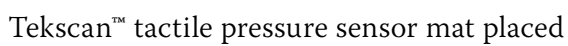
underneath the footings. A top view of the model footing superimposed over the pressure mat is illustrated in Figure 7, together with a $3 \mathrm{D}$ view of a measured contact stress distribution. The active area of the pressure sensor was smaller than the footing footprint, as shown in Figure 7.

Figure 8 illustrates qualitative measurements of the pressure distribution across half the width of the aluminium footings tested at an applied load of $10 \mathrm{kN}$ (contact stress $444 \mathrm{kPa}$ ). In general, despite some scatter, three classes of behaviour can be identified: Stiff footings showed a slightly concave pressure distribution, increasing from the centre towards the footing edge, but for practical purposes this pressure distribution can be taken as approximately constant. Semi-stiff footings showed a slightly convex pressure distribution, reducing slightly from the centreline towards the edge. The semi-flexible (3 $\mathrm{mm}$ deep) footing showed a pressure distribution reducing approximately linearly towards the edge. Due to excessive bending, the edges actually lifted upwards, losing contact with the sand. The area of maximum pressure near the footing centreline coincided with the width of the column.

With increasing load, the shape of the pressure distribution under the more flexible footings evolved somewhat, as reported by Arnold et al (2010). Upon very first load application, the contact stress distribution was approximately uniform. With further load the stress distribution became approximately trapezoidal, reducing from the centre towards the edges (see Figure 8). As load increased further, the shape of the contact stress distribution became approximately triangular (see Figure 8, $3 \mathrm{~mm}$ thick footing), as bending of the footing occurred and the sides of the footing lifted off the sand surface. Contact stress distribution with increasing load for the more flexible footings is presented conceptually in Figure 9. The reduction in contact stress under the footing edges during loading became less as the footing depth increased, as discussed below.

The measured stress distributions illustrate that the assumption of a uniform pressure distribution is only approximately

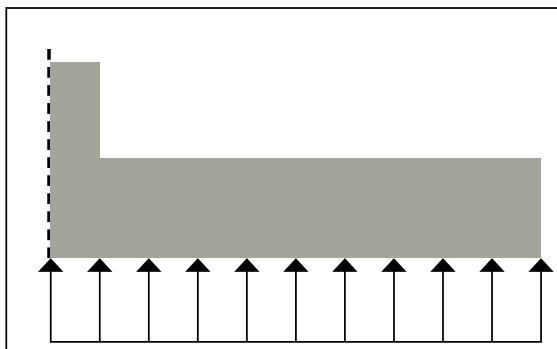

(a) Uniform distribution

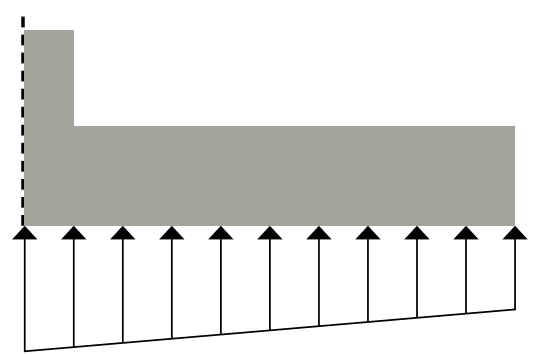

(b) Trapezoidal distribution

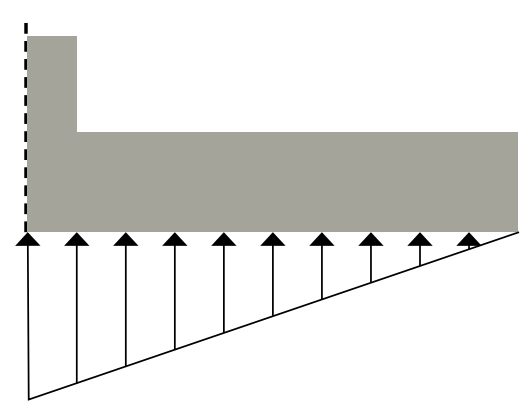

(c) Triangular distribution

Figure 9 Idealised pressure distributions under footings

valid for stiff foundation systems, and that the pressure distributions vary somewhat depending on the stiffness of the foundation and the applied load.

\section{DISCUSSION OF RESULTS}

\section{Settlement and contact stress distribution as a function of footing stiffness}

The normalised settlements of the footings measured at the edge of the column at various loads are illustrated as functions of footing bending stiffness $(E I)$ in Figure 10. The bending stiffness values used in the graphs are those of the model footing and not the prototype footing (the scale factor from an aluminium model to concrete prototype stiffness is $N^{4} E_{A l} / E_{c o n}$ or approximately 290000 , where $N$ is the model scale factor of 30 and $E_{A l}$ and $E_{c o n}$ the Young's moduli of respectively aluminium and concrete). The stiffness values are presented on a logarithmic scale due to their large range. Data from the $3 \mathrm{~mm}$ footing is not presented beyond an applied load of $15 \mathrm{kN}$, as the footing could not be loaded beyond this value due to excessive bending. The density of the sand in the 


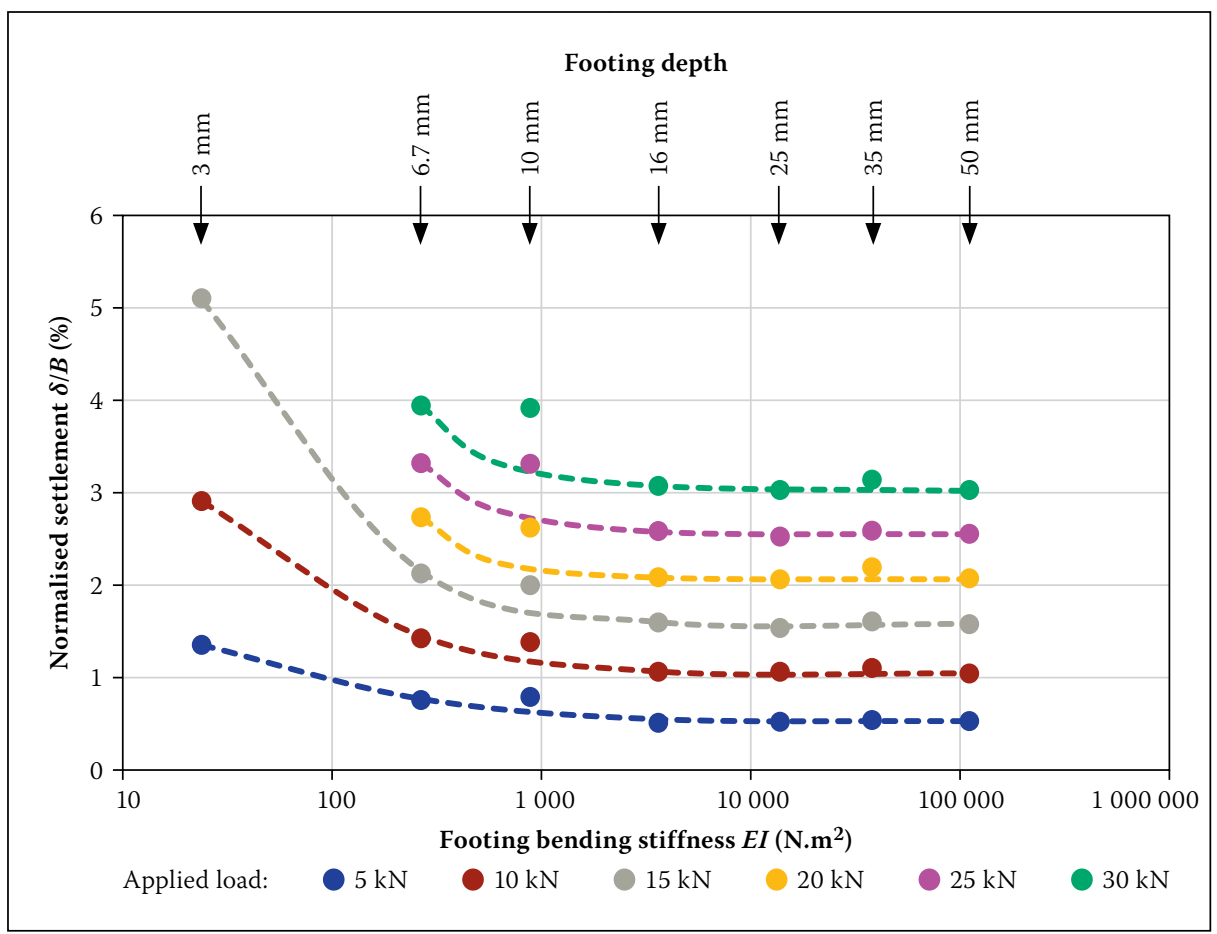

Figure 10 Settlement at the column edge as a function of footing bending stiffness (aluminium footings)

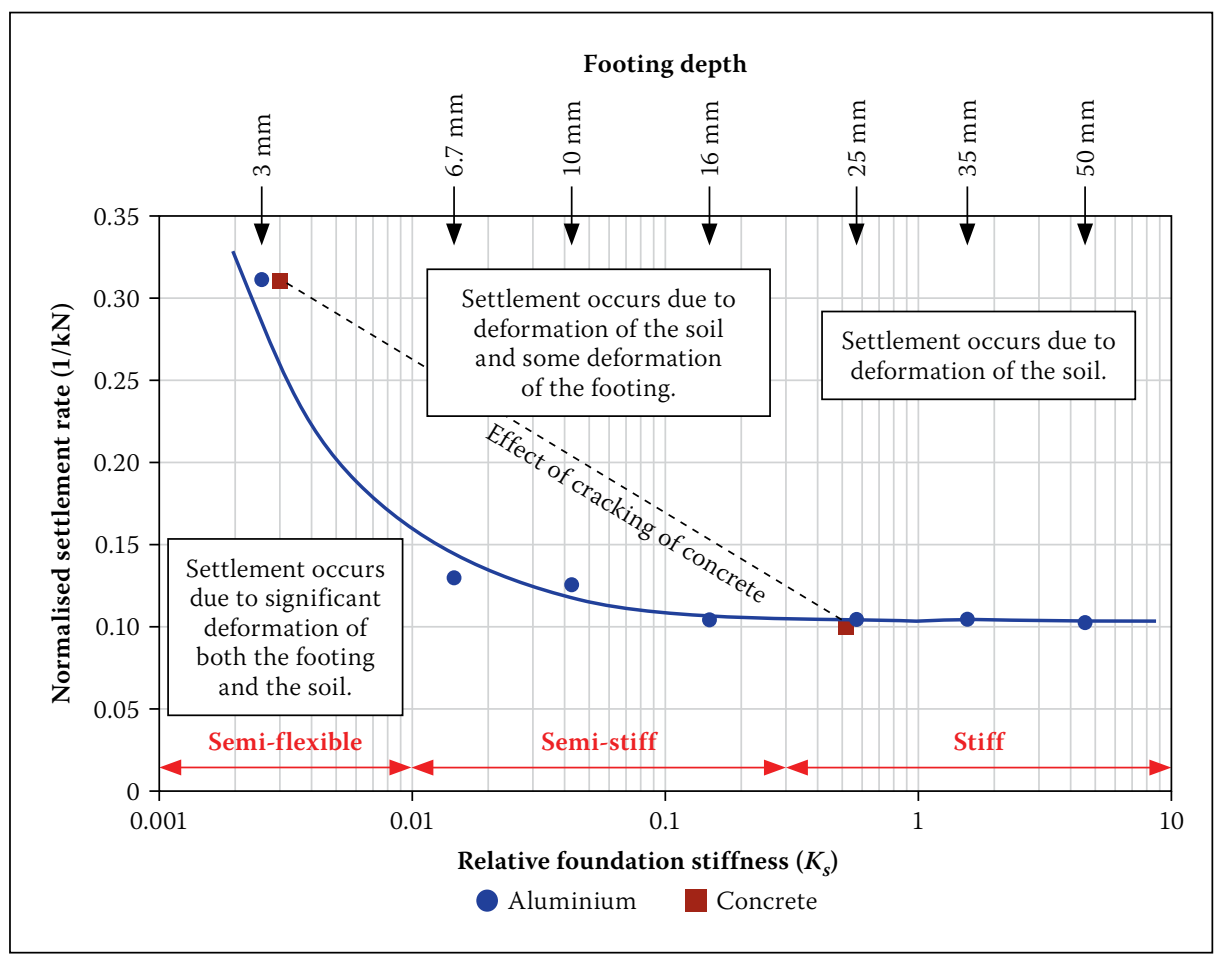

Figure 11 Settlement rate as a function of the relative foundation stiffness $K_{s}$

test on the $10 \mathrm{~mm}$ deep footing was less than in the other tests, resulting in these results falling somewhat outside the general trend observable in Figure 10.

Consider any applied load in Figure 10. Increasing the footing's bending stiffness resulted in a reduction in the settlement measured at the column, but only up to a point. The results in Figure 10 suggest that there is no benefit in using a footing stiffer than the $16 \mathrm{~mm}$ footing. For this footing the relative foundation stiffness classified as stiff (i.e. a $K s$ value exceeding 0.1 , refer to
Table 1). The implication for design is that a footing just needs to be made deep enough to meet the relative stiffness classification of "stiff" (Table 1).

Figure 11 illustrates the slope of the load-settlement curve for the various footings from Figure 4 plotted against the relative foundation stiffness $K_{s}$. (The slope of the load-settlement curve is represented by the settlement measured at the column expressed as a percentage of the footing width divided by load in $\mathrm{kN}$ ). Starting with a low $K_{s}$ value, settlement with load reduces rapidly with increasing foundation stiffness and then stabilises, becoming practically independent of foundation stiffness once the foundation classifies as stiff. This implies that, as soon as the stiffness of the footings was sufficient for the foundation to classify as stiff, the behaviour of the footings was similar and independent of actual relative foundation stiffness, with settlement controlled by the properties of the sand. The model tests indicate that this occurred at $K_{s}$ values exceeding 0.3 , as discussed below, and this value represents the benchmark that a designer would want the foundation to exceed. In the case of semi-flexible and semi-stiff foundations, the settlement was dependent on both the deformation of the footing and the sand.

\section{Cracking of concrete}

The response of the concrete footing during loading is also illustrated in Figure 11. The settlement of the uncracked reinforced concrete footing, measured at the column, was similar to that of the stiff aluminium footings, but once the concrete had cracked, the column settlement increased to that of a semi-flexible aluminium footing. This occurred well within the working contact stress range as discussed previously.

\section{Contact stress distribution}

The effect of footing stiffness on the measured contact stress distributions underneath the footing is illustrated in Figure 12. The figure presents the contact stress measured at the edge of the footing as a percentage of the contact stress measured under the centre of the footing plotted against the relative foundation stiffness. The $3 \mathrm{~mm}$ deep footing was sufficiently flexible that stress was not measured under its edges during load application. The $25 \mathrm{~mm}, 35 \mathrm{~mm}$ and $50 \mathrm{~mm}$ deep footings experienced an approximately uniform pressure distribution, with the pressure under the edge similar to the pressure under the centre of the footing. These footings classified as stiff-based on their relative foundation stiffness. The $16 \mathrm{~mm}$ deep footing also classified as stiff according to Table 1 with a $K_{s}$ value exceeding 0.1, but experienced a reduced pressure below the edge, indicating that it did not behave as entirely stiff. With further reduction in footing depth, the pressure registered under the footing edges reduced further. This illustrates that the assumption of a uniform contact stress distribution (in effect the Winkler model) is only valid for stiff footings which do not deform appreciably, which correlates with the findings of Morfidis and Avramidis (2002). Fitting tentative bounds around the contact stresses recorded at the footing edges 


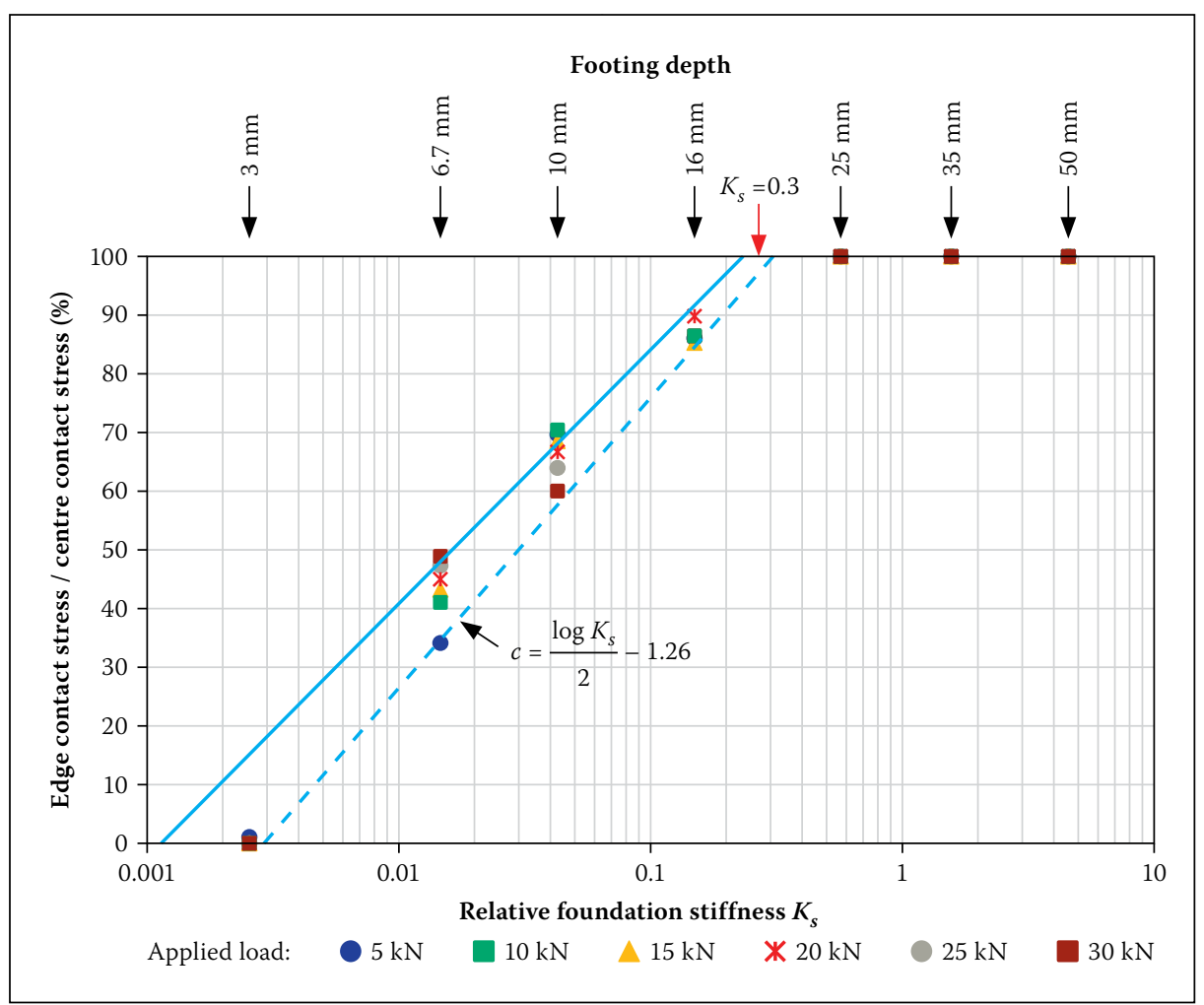

Figure 12 Effect of footing bending stiffness on stress distribution under footings

in Figure 12 and extrapolating suggest that, for perfectly stiff conditions, the relative stiffness $K_{s}$ should exceed 0.3.

\section{Predicting bending moment in the footing}

Stress measurement underneath the model footings showed that, for stiff foundation systems $(K s>0.3)$, the contact stress underneath the footings can be taken as approximately uniform. As the relative stiffness reduces into the semi-stiff range, the contact stress underneath the footing edge as a percentage of the maximum reduces. When the stiffness reduces further to semi-flexible, the contact stress at the edge approaches zero and the edge may even lift up. It would be beneficial to be able to predict the contact stress distribution as a function of the relative foundation stiffness, as the contact stress distribution affects the bending moment that the footing has to be designed for.

Figure 12 shows that the contact stress at the edge of the footing, as a percentage of the maximum stress, does not change much during loading. It also shows that, across a range of relative stiffness values, the contact stress at the footing edge as percentage of the maximum varies approximately linearly with the logarithm of the relative foundation stiffness $K_{s}$. Let the ratio between the contact stress under the edge of the footing versus the maximum value occurring under the centre be represented by $c$. It is proposed that $c$ varies linearly with the logarithm of the relative foundation stiffness from zero at a value of 0.003 to 1 at a value of 0.3 as shown in Figure 12. This relationship is described by Equation 3:

$c=\frac{\log K_{s}}{2}-1.26$

Let $a$ represent the maximum contact stress under the footing centreline and $b$ the footing width. The maximum bending moment per unit length occurring under the centreline of the footing, assuming a trapezoidal distribution (see Figure 9b), is then:

$M=\frac{a b^{2}}{24}(1+2 c)$

For a stiff footing the pressure distribution is uniform and $c=1$ so that the bending moment $M=a b^{2} / 8$. With a reduction in relative stiffness to semi-flexible, $c$ reduces to zero, but under the same vertical load $a$ increases by a factor of 2 so that the bending moment becomes $M=a b^{2} / 12$. The bending moment in a footing forming part of a semi-flexible foundation can therefore be as little as two-thirds of the moment in footing which is part of a stiff foundation. In addition, using the correct stress distribution, the deflected shape of the footing can be calculated more accurately than a result simply based on the assumption of a uniform stress distribution.

\section{Relative foundation stiffness "stiff" versus "semi-stiff"}

Although the boundary between stiff footings and semi-stiff footings is given by the
Canadian Foundation Engineering Manual (2006) as a $K_{s}$ value of 0.1 , the $16 \mathrm{~mm}$ footing $\left(K_{s}\right.$ value of 0.15$)$ did not exhibit the same behaviour as the stiff footings. Therefore, it is suggested that the proposed lower boundary to which a uniform pressure distribution is valid is adjusted upward from a $K_{s}$ of 0.1 to a value of 0.3 . Even at conventional loads (equivalent to $5 \mathrm{kN}(222 \mathrm{kPa})$ or $10 \mathrm{kN}$ (444 kPa)) semi-stiff footings still showed reduced stress under the edges, not behaving as stiff as shown in Figure 12.

\section{CONCLUSIONS AND \\ RECOMMENDATIONS}

The following conclusions from the model study are presented:

- The relative stiffness of a foundation system affects the deflection of and contact stress distribution beneath the footing. The contact stress distribution beneath footings in a stiff foundation on dense sand is approximately uniform. A reduction in stiffness results in the footing bending during loading, which reduces the contact stress at the footing edges.

- The contact stress distribution beneath a footing plays an important role in not only the settlement and deflection behaviour of the footing, but it affects the bending moments in the footing that the structural engineer needs to design for.

- The results presented suggest that the optimum depth of a footing is that depth resulting in the foundation just classifying as stiff, i.e. corresponding to a relative foundation stiffness $K_{s}$ of 0.3 . For this, and higher stiffnesses, the contact stress distribution under a strip footing can be assumed to be approximately uniform.

- The behaviour of an initially stiff concrete footing will become more flexible after the onset of cracking. This can occur well below the allowable bearing capacity of the foundation. The settlement undergone by a column bearing on such a footing will then depend on both the deformation of the underlying soil and the deformation of the footing. The contact stress at the footing edges will reduce so that the maximum stress under the foundation will increase if the footing still has to support the same load. This situation appears less optimal than the behaviour of a stiff foundation. The recommendation is therefore that foundations be designed to have a relative foundation stiffness classifying as "stiff", i.e. a $K_{s}$ value of 0.3. It does not appear that increasing the stiffness beyond this value is beneficial. 


\section{REFERENCES}

Aiban, SA \& Znidarčic, D 1995. Centrifugal modeling of bearing capacity of shallow foundations on sands. ASCE Journal of Geotechnical Engineering, 121(10): $704-712$.

Algin, H M 2007. Practical formula for dimensioning a rectangular footing. Engineering Structures, 29(1): 1128-1134.

Archer, A 2014. Using small-strain stiffness to predict the settlement of shallow foundation on sand. MEng dissertation, University of Pretoria.

Arnold, A, Laue, J, Espinosa, T \& Springman, S M 2010. Centrifuge modelling of the behaviour of flexible raft foundations on clay and sand. In: Springman, S M, Laue, J \& Seward, L (Eds.), Physical Modelling in Geotechnics. Proceedings of the 7th International Conference on Physical Modelling in Geotechnics (ICPMG 2010) held in Zurich. London: Taylor and Francis, 679-684.

ASTM (American Society for Testing and Materials) 1996a. ASTM D4253 -93: Test Methods for Maximum Index Density and Unit Weight of Soils Using a Vibratory Table. West Conshohocken, PA: ASTM International.

ASTM (American Society for Testing and Materials) 1996b. ASTM D4254 -91: Standard Test Method for Minimum Index Density and Unit Weight of Soils and Calculation of Relative Density. West Conshohocken, PA: ASTM International.

Baumann, R A \& Weisgerber, F E 1983. Yield-line analysis of slabs-on-grade. Structural Engineering Journal, 109(11): 1553-1567.

Brinch Hansen, J 1968. A revised extended formula for bearing capacity. Danish Geotechnical Institute Bulletin, No. 28. Brabrand, Denmark.
Brown, R, Valsangkar, A J \& Schriver, A B 2004 Centrifuge modeling of surface footings on a sand layer underlain by a rigid base. Geotechnical and Geological Engineering 22: 187-198.

BSI (British Standard) 2015. BS 8004:2015: Code of Practice for Foundations. London: British Standards Institution.

Canadian Foundation Engineering Manual, 4th ed. 2006. Richmond, BC, Canada: Canadian Geotechnical Society.

Conniff, D E \& Kiousis, P D 2007. Elastoplastic medium for foundation settlements and monotonic soilstructure interaction under combined loadings. International Journal for Numerical and Analytical Methods in Geomechanics, 31(1): 789-807.

Haigh, S K, Houghton, N E, Lam, S Y, Li, Z \& Wallbridge, P J 2010. Development of a 2D servoactuator for novel centrifuge modelling. In: Springman, S M, Laue, J \& Seward, L (Eds.), Physical Modelling in Geotechnics. Proceedings of the 7th International Conference on Physical Modelling in Geotechnics (ICPMG 2010) held in Zurich. London: Taylor and Francis, 239-244.

Hemsley, J A 2000. Design Application of Raft Foundations. London: Thomas Telford.

Knappett, J A, O’Reilly, K, Gilhooley, P, Reid, C \& Skeffington, K 2010. In: Springman, S M, Laue, J \& Seward, L (Eds.), Physical Modelling in Geotechnics. Proceedings of the 7 th International Conference on Physical Modelling in Geotechnics (ICPMG 2010) held in Zurich. London: Taylor and Francis, 141-146.

Kusakabe, O 1995. Foundations. In: Taylor, R N (Ed.), Geotechnical Centrifuge Technology, London: Blackie Academic and Professional, 118-165.
Meyerhof, G G 1963. Some recent research on the bearing capacity of foundations. Canadian Geotechnical Journal, 1(1): 16-26.

Milovic, D M, Touzot, G \& Tournier, J P 1970. Stresses and displacements in an elastic layer due to an inclined eccentric load over a rigid strip. Geotechnique, 20(3): 231-252.

Morfidis, K \& Avramidis, I E 2002. Formulation of a generalised beam element on a two-parameter elastic foundation with semi-rigid connections and rigid offsets. Computers and Structures, 80(1): 1919-1934.

Pisanty, A \& Gellert, M 1972. Automatic design of sloped spread footings. Building Science, 7(1): 53-59.

Schofield, A N 1980. Cambridge geotechnical centrifuge operations. Geotechnique, 30(3): 227-268.

Skorpen, S \& Dekker, N 2014. The application and interpretation of linear finite element analysis results in the design and detailing of hogging moment regions in reinforced concrete flat plates. Journal of the South African Institution of Civil Engineering, 56(1): 77-92.

Tekscan ${ }^{\mathrm{TM}}$ 2014. Sensor Model 5105. Available at: http://www.tekscan.com/5101-pressure-sensor. (Accessed on 29 October 2014).

Westergaard, H M 1925. Stresses in concrete pavements computed by theoretical analysis. Public Roads, 7: 25

Westergaard, H M 1937. What is known of stresses. Engineering News Record, 118(1): 26-29.

White, D J, Take, W A \& Bolton, D 2003. Soil deformation measurement using particle image velocimetry (PIV) and photogrammetry. Geotechnique, 53(7): 619-631. 